\title{
TOPICAL CORTISONE IN SYPHILITIC INTERSTITIAL KERATITIS* REVIEW OF TWENTY-THREE CASES (29 EYES)
}

BY

\author{
GORDON O. HORNE
}

From the Department of Venereal Diseases, Generai Infirmary, Leeds

There is still considerable dubiety about the role of cortisone in the treatment of syphilitic interstitial keratitis, and in current practice it is not always used in this condition (or is used in inadequate dosage) although supplies are freely available. Among the reasons for this reluctance to use cortisone are the following :

(1) Ignorance of its Value.-This has led to scepticism of good results that have been reported.

(2) Contradictory Verdicts on its Value in the Literature.-Two years ago Woods (presumably representing American opinion) wrote that " syphilologists and ophthalmologists doubt whether cortisone therapy in interstitial keratitis is a justifiable procedure" (Woods, 1952a). Also in America Purnell and Leopold (1952) included syphilitic interstitial keratitis in the list of ocular conditions " not improved" by cortisone. Klauder and Meyer (1954) wrote that in the light of their experience they had stopped using cortisone in this condition. At a discussion on a paper on this subject read in November, 1952, at a meeting of the Medical Society for the Study of Venereal Diseases, caution was expressed about its value (Ashworth, 1953). Minton (1952) did not include syphilitic interstitial keratitis in a list of conditions "responding favourably" to cortisone. On the other hand, many apparently excellent results have been reported, for example by Crane and McPherson (1951), Salomaa and Swanljung (1952), Ashworth (1953), Drews, Barton, and Mikkelsen (1953), Oksala (1953), and North (1954).

These contradictory and frequently pessimistic reports on cortisone in interstitial keratitis are probably due to several factors :

(a) Conclusions drawn from small and unrepresentative series of cases, and in particular from its use in some cases in which improvement could not be expected-

\footnotetext{
* Received for publication September 3, 1954.
}

for example, where there were corneal scars or necrosis (Woods, 1950).

(b) Its frequent use in inadequate dosage. Excellent immediate results have been obtained even in severe cases when adequate dosage was used, and especially when the patients were hospitalized initially, as in the series of Crane and McPherson (1951), Salomaa and Swanljung (1952), Ashworth (1953), Drews and others (1953), and North (1954).

(c) A misunderstanding of what can be expected of cortisone, and in particular the unfair verdict of failure applied when relapses occur after the withdrawal of the hormone (even an attack in the other eye after successful treatment of the first eye has been held against cortisone).

(d) Difficulty in interpreting the results of treatment, illustrated by the comment by Lister (1953) that in one of the series of Drews and others (1953) there was a recrudescence a few days after stopping cortisone when it had been used continuously for about 8 months, and that " 8 months is an exceptionally long period for one attack. This supports Woods's suggestion that cortisone delays or prevents the development of a natural resistance to the disease". In view of the notoriously variable behaviour of interstitial keratitis, a conclusion on the basis of one case is not justified, and, in any event, the recurrence after withdrawal of cortisone might equally well have been a true relapse and not necessarily a continuation of the original attack.

(e) Premature judgment of the value of cortisone. For example, Klauder and Meyer (1954) appear to have condemned the local instillation of cortisone as a result of experience of thirteen patients ( 21 affected eyes) treated over a period of about 18 months.

(3) Exaggerated Fear of the Side-effects of Cortisone.- Systemically administered cortisone can have undesirable side-effects, but there is no reason to believe on theoretical grounds that it would have any such effects when administered topically to the eyes, and none has been recorded (see especially Steffensen, 1952; Drews and others, 1953). Current topical preparations of the hormone seldom cause local reactions, and irritation attributed to too strong a suspension can be overcome by dilution. 
(4) Repeated Authoritative Warnings by Woods (1951, 1952a, b) of Possible Dangers in Syphilitic Interstitial Keratitis.-Woods (1952a) rightly points out that the use of cortisone is potentially dangerous (unless other adequate specific therapy is available) in infections of the cornea resulting from " invasion of the tissues by the exciting micro-organisms" (abscess of the cornea and tuberculosis are cited as examples). In interstitial keratitis, however, there is seldom (if ever) evidence of invading organisms, and the condition has many of the characteristic features of a pure " hypersensitivity" phenomenon. In any case penicillin is a very potent spirochaeticide and its use coincidentally would discount any hypothetical danger from cortisone given alone. However, the literature already indicates that cortisone can be highly effective in interstitial keratitis (at least judging by immediate results) with or without penicillin (see Drews and others, 1953), and no undesirable local effect has been recorded.

Woods's other warning, that prevention of vascularization of the cornea (which he claims is important for healing and for the development of immunity) may result not only in prolonging an attack but in frequent recurrences, can only be finally answered after observations extending over many years. Klauder and Meyer (1954) appear to have discarded topical cortisone because they support Woods's views, and interpret their results as meaning that cortisone has a deleterious effect, but there is little other evidence so far to substantiate this view. Crane and McPherson (1951) treated seventeen eyes with a 10-day course of topical cortisone, in six of them before vascularization had occurred; in their short observation period they found that only two of the six which had shown no vascularization relapsed, whereas six of the eleven eyes which had shown vascularization did relapse. Other authors (including Drews and others, 1953) have had good results even in the very early stages of the disease before vascularization had occurred.

The argument of Klauder and Meyer (1954), that the use of cortisone, in their experience, is followed by a high incidence of recurrences, and is objectionable because it involves longer hospitalization and greater expense and incapacitation, can be easily refuted, since even prolonged treatment with topical cortisone is relatively inexpensive and can be carried out at home, and, provided it suppresses the inflammation, does not lead to incapacitation. Their alternative method of treatment-artificial fever, thyroid, and possibly testosterone-would appear to be more likely to involve hospitalization, expense, and even incapacitation. It can be argued that any number of recurrences (each of which can be promptly controlled by cortisone), but with maintenance of good vision, is preferable to no recurrence at the expense of prolonged distress, vascularization of the cornea, scarring, and permanently impaired vision. The iridocyclitis that accompanies interstitial keratitis may also contribute to impaired vision, and this also can be prevented by cortisone.

Cortisone has been available for the treatment of syphilitic interstitial keratitis for about 4 years, and whilst, because of the natural history of the disease, it is premature to attempt a final assessment of its value, there would appear to be an indication for a review of the information acquired so far. Published reports include a considerable number of small series of cases, and a few larger series. Most of these deal only with the more or less immediate effects of cortisone, and there are few reports of observations continued for longer than about a year after the start of treatment.

It is the intention here to discuss briefly the following points :

(1) the expected effects of cortisone on the natural history of syphilitic interstitial keratitis ;

(2) the practical aspects of its use in this disease ;

(3) the place of systemic antisyphilitic therapy ;

(4) the methods of assessing the effect of cortisone.

Experience recorded in the literature will be referred to when relevant to the points discussed. Then a report will be given of 23 patients (29 affected eyes) treated between December, 1950, and January, 1954, nearly all of whom are still under observation. A brief preliminary report of twenty of these patients has already been published (Horne, 1954a). Finally, conclusions will be drawn as to the role of cortisone and the best way of using it in the treatment of interstitial keratitis.

\section{Expected Effects of Cortisone on the Natural History of Interstitial Keratitis}

(a) Manifestations of the Attack.-Cortisone suppresses the manifestations of inflammation, irrespective of the aetiology, but is particularly effective when the inflammation is of the "hypersensitivity" type. It has also been shown experimentally to prevent vascularization of the cornea following various forms of noxious agents. Since there is a great deal of evidence that syphilitic interstitial keratitis is an inflammation of the " hypersensitivity" type, and the attacks are selflimiting (though of variable duration), cortisone should control the signs and symptoms of this condition. The earlier cortisone is started after the onset of inflammation the better would be the result; cortisone has no effect on fibrotic or necrotic tissue. 
In view of the ready accessibility of the tissues involved, local application of the hormone should be effective. Withdrawal of cortisone before the end of the "attack" (i.e. before the hypersensitivity phase in the cornea had ceased) should be followed by a recurrence of activity. Similar effects would be expected in the iridocyclitis that frequently accompanies interstitial keratitis. All these phenomena have been observed to occur.

(b) Duration of Attack.-In view of what is known about the action of cortisone and about the pathology of interstitial keratitis, it is difficult to speculate whether cortisone would have any effect on the duration of an attack (the views of Woods have been referred to), and clinical experience may not elucidate this problem. Great variation occurs in individual cases and adequate controls cannot be obtained, since it is not now justifiable to withhold cortisone for this purpose. Comparison in this respect with series from pre-cortisone days would be difficult to interpret. Even comparisons in the same patient in whom one eye was treated in the pre-cortisone days and one treated with cortisone are of limited value, because of the differences known to occur even when two such eyes are treated at different times with the same methods. In any case, since cortisone suppresses the manifestations of an attack for so long as it is given, it would be almost impossible to know how long an attack lasted unless the hormone were given in very short interrupted courses.

(c) Incidence of Relapses and Recurrences.-Here also it is difficult to speculate on the effect of cortisone (the views of Woods have been referred to), but it should be borne in mind that the hormone cannot "cure" any disease. Comparison with series treated in pre-cortisone days is complicated by the possible influence of differing schedules of systemic antisyphilitic treatment, although the general opinion appears to be that even penicillin has little, if any, more influence on the relapse rate than the chemotherapy which preceded it.

Another difficulty in assessing the possible influence of cortisone on the duration of attacks and on the incidence of relapses is that of differentiating between the two. In some reported analyses an arbitrary time of freedom from activity (such as a year) was demanded before a relapse was allowed. However, if cortisone is used for a considerable period of time with successful suppression of the inflammation, which starts again on withdrawal of cortisone, it may be impossible to be certain whether this is the same attack or a relapse*.

\footnotetext{
* See the comment of Lister (1953) discussed earlier.
}

(d) Ultimate Visual Acuity.-Permanent impairment of vision after interstitial keratitis results from one or more of the following factors :

Opacities and vascularization of the cornea.

Corneal dystrophies and changes in its curvature leading to refractive errors.

Keratic precipitates.

Various sequelae of the accompanying iridocyclitis.

If the inflammatory phase can be completely suppressed by cortisone, irreversible tissue changes should be avoidable, and these sequelae should not occur. If cortisone is started early and is maintained during the whole of the active stage of the disease, there should be no residual damage to the eye and vision should not be impaired.

(e) Involvement of the Other Eye.-It is difficult to believe that local application of cortisone to one eye could influence the natural history of the disease as it affects the other eye, since the amount used is not adequate to have any systemic effect. Confirmation of this, were it needed, is provided by Drews and others (1953) who in some cases used cortisone in alternate eyes when both were involved, and found that there was no effect on the eye not treated ; also, in other cases of theirs (and of other authors), the second eye became involved whilst the first eye was under treatment with cortisone. Comparison in this respect with series from precortisone days is beset with all the well-known difficulties of such a procedure, some of which have been discussed. The literature shows that "the chance of escaping bilateral involvement increases in direct ratio to the lapse of time from the onset of interstitial keratitis in the first eye" (Klauder and Vandoren, 1941). Different series show that if the second eye is to become involved, this will occur within 2 years in between 70 and 95 per cent. of cases. Opinions differ as to the effect of antisyphilitic treatment on the incidence of involvement of the second eye, but it is worth noting that the American Cooperative Clinical Group (Cole and others, 1937) concluded that "adequate" antisyphilitic treatment, especially if given early in the course of the involvement of the first eye, might have some influence in preventing the involvement of the second eye.

\section{Practical Aspects of the Use of Cortisone in} Interstitial Keratitis

(a) Parenteral Administration.--There are about a dozen reports of cases of interstitial keratitis treated with ACTH or parenteral cortisone, but there is no doubt that local administration is the method of choice. It is more effective, and the undesirable side-effects of parenteral administration are avoided. 
(b) Local Administration.-There has been no adequate assessment of the relative merits of the different methods of local administration of cortisone in interstitial keratitis. Most reports have described the results of treatment with drops only. Duke-Elder and others (1951) concluded that " in diseases limited to the cornea, the instillation of drops appears to be more effective than subconjunctival injections. Drops or ointment, or a combination of both, seem to be the method of choice". Purnell and Leopold (1952) had disappointing results in seven out of eight cases treated with subconjunctival injections. Lavery (1952) stated that cases responded to ointment and subconjunctival injections with equal rapidity. Drews and others (1953) gained the impression that in two of their cases in which ointment ( 1.5 per cent.) was used the clinical response was less rapid than that produced by the instillation of drops in their other sixteen cases. Klauder and Meyer (1954) found subconjunctival injections "of questionable benefit" in their six cases.

One possible limitation of topical treatment should be borne in mind. Drews and others (1953) described a case (Case 6) in which a patient with severe bilateral interstitial keratitis, with intense photophobia, blepharospasm, and lacrimation, failed to respond in the expected way even after several days of hourly drops, but eventually responded promptly to artificial fever. They suggested that the failure of topical treatment may have been due to the intense lacrimation washing away the cortisone.

(c) Time of Administration.-In view of what is known of the pathology of interstitial keratitis and of the mode of action of cortisone, it would be expected that the earlier in the course of the disease it is used, the better the results (the contrary views of Woods have been referred to). This has been the experience of those who have commented on this aspect of the problem (for example, Crane and McPherson, 1951 ; Duke-Elder and others, 1951). Drews and others (1953) stated that " in several cases treated early in the course of the disease it later became impossible to detect any evidence of interstitial keratitis by slit-lamp examination". Prevention of the development of the characteristic features of interstitial keratitis by the early use of cortisone has a theoretical disadvantage, since it may render more difficult the certain diagnosis of congenital syphilis (an example of a case of this kind has been reported by Horne, 1954b), but this is outweighed by the advantages of the early suppression of the interstitial keratitis. (d) Cortisone and Hydrocortisone.-Assessment of the respective merits of cortisone (Compound $\mathrm{E}$ ) and hydrocortisone (Compound F) in ophthalmology is difficult, if only because of the high degree of effectiveness of each of them. The general opinion appears to be, however, that in most conditions hydrocortisone is the more effective (Steffensen, Ivy, and Nagle, 1952; Gordon, McLean, and Koteen, 1953 ; Laval, 1953; McDonald, Leopold, Vogel, and Mulberger, 1953 ; Gordon, 1954), and it should always be tried if cortisone fails to give good results. No information is available on their relative merits in syphilitic interstitial keratitis in particular.

(e) Dosage.-Cortisone does not obey the " allor-none" rule, and there is clinical and laboratory evidence that its effect is "quantitative "-the more severe the inflammation the greater the concentration required. Failure to appreciate this has probably helped to account for the mediocre and poor results reported by some observers. Those who have used intensive treatment (hourly or 2hourly drops), and especially those whose patients were admitted to hospital initially (i.e. where the regular administration of adequate dosage has been ensured), have reported the greatest success (Salomaa and Swanljung, 1952 ; Ashworth, 1953 ; Drews and others, 1953, North, 1954).

(f) Duration of Treatment.-In view of the natural history of interstitial keratitis, with its attacks of unpredictable length, it would be impossible to estimate how long cortisone is required in any particular case. Dosage should obviously be maintained at a level intensive enough to control completely all activity of the disease, but it would be difficult to decide, without trial, when to stop cortisone. The duration of treatment must therefore be individualized and to a certain extent be empirical, and different authors have applied different principles. Ashworth (1953), for example, concluded that "it seems necessary to prolong treatment for at least 3 months.". As would be expected, others have had success in some cases with shorter spells of treatment. Failure to appreciate this aspect of the problem has probably accounted for the scepticism of some authors.

\section{Role of Systemic Antisyphilitic Treatment}

It is generally agreed that systemic penicillin has little or no effect on interstitial keratitis, either on the progress of individual attacks or on the incidence of recurrences (see especially Klauder, 1951 ; Drews and others, 1953). It is premature to draw final conclusions, however, and there is some 
evidence (already referred to) that adequate treatment of congenital syphilis does at least reduce the incidence of involvement of the second eye. Nevertheless, the treatment of all cases of congenital syphilis, whether interstitial keratitis is present or not, must include the use of penicillin. The only problem is whether there is any potential danger in using cortisone without the coincidental "cover" of systemic penicillin. The significance of this has already been mentioned, and it has been pointed out that cortisone alone should carry no risk of aggravating the condition. Personal experience and records in the literature show that topical cortisone can be given effectively in interstitial keratitis for considerable periods without systemic penicillin, and that recurrences can be adequately controlled by cortisone alone when the initial attack has been treated with cortisone with or without systemic penicillin.

\section{Assessment of the Beneficial Effects of Cortisone in Interstitial Keratitis}

The effects of cortisone on syphilitic interstitial keratitis and its value in the treatment of this condition can be assessed in terms of immediate and long-term results. There is no doubt from experience already recorded in the literature that topical cortisone can have a very beneficial immediate effect in interstitial keratitis and accompanying iridocyclitis, the more severe the inflammation the more dramatic the results. Subjectively, it completely relieves pain, photophobia, and lacrimation, sometimes within a few hours, and usually within a few days, and impaired vision is rapidly restored. This prompt relief of distressing symptoms has important psychological implications, since the long-term effects of prolonged distress (including the fear of blindness) notoriously associated with interstitial keratitis in the past, and aggravated by the youth of the majority of those afflicted, can now be eliminated.

Objectively, the evidence of active inflammation usually subsides within a few days, particularly the circumcorneal injection, corneal oedema, and early infiltration, and any accompanying iridocyclitis. If dense infiltration and vascularization of the cornea and keratic precipitates have been allowed to develop, these take longer to resolve even in intensively treated cases, and vessels may persist for a long time. Cortisone would not be expected to have any effect on established scars or on necrotic tissue. Withdrawal of cortisone, as would be expected, is sometimes followed by a recrudescence of the symptoms and signs.

Comparison of the immediate effects of cortisone on acute attacks of interstitial keratitis may be difficult to analyse statistically, but the relief of symptoms and suppression of inflammation are so rapid in nearly every case in which adequate dosage is used that strictly comparable series are not required before the conclusion can be drawn that in this respect cortisone is much superior to any method of treatment used hitherto.

In the long-term assessment the most important criterion is visual acuity. Other factors to be considered are, of course, the incidence of recurrences (although, as has been pointed out, this is less important) and the cosmetic appearance of corneal scars. In assessing visual acuity, correction for refractive errors must be made, and care must be taken to avoid debiting against interstitial keratitis defects due to choroiditis, since the two frequently co-exist.

The final visual acuity offers the most clear-cut method of assessing the relative merits of different types of treatment, although this criterion also is not without its difficulties. Results will obviously depend to some extent on the time of the assessment in relation to the onset of the disease. If the period is very short the possible effects of later recurrences cannot be considered; but, on the other hand, it is known that some corneal opacities may be slowly absorbed spontaneously over long periods of time, with coincidental improvement in visual acuity.

\section{Clinical Investigation}

Clinical Material.-This comprised 23 patients with syphilitic interstitial keratitis ( 29 affected eyes) attending the Department of Venereal Diseases, General Infirmary, Leeds, who started treatment with local cortisone between December, 1950, and January, 1954. They remained under observation for periods varying from 6 to 39 months. In none was there any doubt about the diagnosis of congenital syphilis, although in one (Case 10) the blood Wassermann reaction was negative. Relevant clinical data are summarized in Tables I, II, and III (overleaf) ; in the section describing the results of Group D three clinical case histories are included. The cases are described as severe, moderately severe, or mild, depending principally on symptoms, severity of involvement of the eye, and visual acuity. The age recorded is that at the time of starting cortisone.

The limitations of busy routine out-patient departments and lack of cooperation from some of the patients are reflected in occasional deficiencies of information. Methods of treatment have necessarily varied as experience has been acquired. For various reasons some cases have not been ideally managed, but all of them have been included in the analysis since those which were less well-treated provide useful information. During the same period cortisone and ACTH have also been used in the treatment of other types of syphilitic 
GROUP A, CORTISONE STARTED DÜRIP

\begin{tabular}{|c|c|c|c|c|c|c|c|c|c|}
\hline \multirow{2}{*}{$\begin{array}{l}\text { Case } \\
\text { No. }\end{array}$} & \multirow{2}{*}{ Sex } & \multirow{2}{*}{$\begin{array}{r}\text { Age } \\
\text { (yrs) }\end{array}$} & \multirow{2}{*}{$\begin{array}{c}\text { Eye } \\
\text { Involved }\end{array}$} & \multirow{2}{*}{$\begin{array}{l}\text { Duration } \\
\text { before } \\
\text { Cortisone } \\
\text { (wks) }\end{array}$} & \multirow{2}{*}{$\begin{array}{l}\text { Date } \\
\text { Cortisone } \\
\text { Started }\end{array}$} & \multirow{2}{*}{ Clinical Data } & \multicolumn{2}{|c|}{$\begin{array}{l}\text { Cortisone Dosage } \\
\text { (hospital periods in italics) }\end{array}$} & $\overrightarrow{\overrightarrow{\text { Sh }}}$ \\
\hline & & & & & & & Frequency & Dates & $\begin{array}{l}\overline{\hat{q}_{i m}} \\
\text { 䛼ays }\end{array}$ \\
\hline \multirow[t]{2}{*}{1} & \multirow[t]{2}{*}{$\mathbf{M}$} & \multirow[t]{2}{*}{12} & $\mathbf{R}$ & 3 & \multirow[b]{2}{*}{10.1 .51} & \multirow{2}{*}{$\begin{array}{l}\text { Severe (C.F. each eye) } \\
\text { Bilateral iridocyclitis and interstitial keratitis, } \\
\text { keratic precipitate }++\end{array}$} & & & 813 \\
\hline & & & $\mathbf{L}$ & 2 & & & $\begin{array}{l}\text { 3-hrly } \\
\text { Three daily }\end{array}$ & $\begin{array}{l}15.2 .51-\tau .3 .51 \\
29.3 .51-24.4 .51\end{array}$ & $\begin{array}{l}0.12 \\
021) \\
0\end{array}$ \\
\hline 2 & $F$ & 44 & $\mathbf{R}$ & 6 & 23.7 .51 & $\begin{array}{l}\text { Moderately severe (C.F.) } \\
\text { Diffuse corneal oedema, no cells in anterior } \\
\text { chamber }\end{array}$ & $\begin{array}{l}\text { Three daily } \\
\text { 4-hrly } \\
\text { Three daily } \\
\text { Four daily }\end{array}$ & $\begin{array}{l}23.7 .51-24.7 .51 \\
25.7 .51-30.7 .51 \\
31.7 .51-4.8 .51 \\
5.8 .51-31.10 .51\end{array}$ & $\begin{array}{l}\vec{\omega}^{13} \\
\tilde{\omega}^{88} \\
=\end{array}$ \\
\hline \multirow[t]{2}{*}{3} & \multirow[t]{2}{*}{$\mathbf{M}$} & \multirow[t]{2}{*}{5} & $\mathbf{R}$ & $4 !$ & 19.9.51 & $\begin{array}{l}\text { Moderately severe (P.L.) } \\
\text { Cornea diffusely infiltrated, no vascularization, } \\
\text { keratic precipitates }+\end{array}$ & $\begin{array}{l}\text { Three daily } \\
\text { 4-hrly } \\
\text { Three daily } \\
\text { Five daily } \\
\end{array}$ & $\begin{array}{l}19.9 .51 \\
20.9 .51-24.9 .51 \\
25.9 .51 \\
3.10 .51-9.10 .51\end{array}$ & $\begin{array}{l}\sum_{0}^{\infty} 7 \\
\sum_{(7)}^{\infty} \\
\end{array}$ \\
\hline & & & $\mathbf{L}$ & Few days & 19.1 .52 & $\begin{array}{l}\text { Mild } \\
\text { Cornea diffusely infiltrated }\end{array}$ & Ung. & 19.1.52-8.3.52 & $\sum^{-50}$ \\
\hline \multirow[t]{2}{*}{4} & \multirow[t]{2}{*}{$\mathbf{M}$} & \multirow[t]{2}{*}{13} & $\mathbf{R}$ & 4 & \multirow[t]{2}{*}{2.5 .52} & \multirow[t]{2}{*}{$\begin{array}{l}\text { Severe bilateral (R.-H.M.; L. }-3,36 \text { ) } \\
\text { Both eyes early vascularization }\end{array}$} & $\begin{array}{l}\text { Five daily } \\
\text { Three daily }\end{array}$ & $\begin{array}{l}2.5 .5 \%-10.5 .52 \\
11.5 .52-17.5 .52\end{array}$ & $\overbrace{\frac{\pi}{T}}^{0} 16$ \\
\hline & & & $\mathrm{L}$ & 3 & & & $\begin{array}{l}\text { Three daily } \\
\text { Two daily } \\
\text { Three daily } \\
\end{array}$ & $\begin{array}{l}18.5 .52-24.5 .52 \\
25.5 .52-31.5 .52 \\
9.6 .52-21.6 .52\end{array}$ & $\begin{array}{l}\overrightarrow{\hat{a}_{4}} \\
\mathrm{v}_{13} \\
\end{array}$ \\
\hline 5 & $\mathbf{F}$ & 29 & L & 4 & 28.8 .52 & $\begin{array}{l}\text { Moderately severe }(6 / 36) \\
\text { Diffuse corneal infiltration with vascularization }\end{array}$ & Three daily & $28.8 .52-14.10 .52$ & 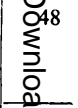 \\
\hline$* 5$ & $\mathbf{M}$ & 23 & $\mathbf{R}$ & Few days & 1.10 .52 & $\begin{array}{l}\text { 1.10.52 Early interstitial keratitis } \\
\text { 15.10.52 Moderately severe (C.F.) } \\
\text { Completely hazy cornea, whole thickness oedema- } \\
\text { tous, no vascularization, ciliary injection }\end{array}$ & $\begin{array}{l}\text { 4-hrly } \\
\text { 2-hrly } \\
\text { Four daily } \\
\text { One daily } \\
\text { Four daily } \\
\text { 2-hrly } \\
\quad \text { (waking } \\
\text { hours) }\end{array}$ & $\begin{array}{l}1.10 .52-27.10 .52 \\
28.10 .52-6.11 .52 \\
7.11 .52-21.11 .52 \\
22.11 .52-20.12 .52 \\
21.12 .52-3.1 .53 \\
21.2 .53-16.3 .53\end{array}$ & 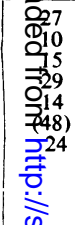 \\
\hline 7 & $\mathbf{M}$ & 27 & $\mathbf{R}$ & Few days & 3.8 .53 & $\begin{array}{l}\text { Severe (P.L.) } \\
\text { Completely hazy cornea, ciliary injection }\end{array}$ & $\begin{array}{l}\text { 2-hrly } \\
\text { Hourly } \\
\text { Four daily } \\
\text { Three daily } \\
\text { Two daily } \\
\end{array}$ & $\begin{array}{l}3.8 .53-18.8 .53 \\
19.8 .53-21.8 .53 \\
92.8 .53-1.9 .53 \\
2.9 .53-9.9 .53 \\
10.9 .53-17.9 .53\end{array}$ & 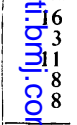 \\
\hline \multirow[t]{2}{*}{8} & \multirow[t]{2}{*}{$F$} & \multirow[t]{2}{*}{7} & L & $3 !$ & 1.10 .53 & $\begin{array}{l}\text { Severe (P.L.) } \\
\text { Dense deep corneal opacity, peripheral punctate } \\
\text { opacities, superficial vascularization at periphery }\end{array}$ & $\begin{array}{l}\text { Hourly } \\
\text { Three daily } \\
\text { 2-hrly Ung. } \\
\text { Four daily }\end{array}$ & $\begin{array}{l}1.10 .53-27.10 .53 \\
28.10 .53-10.11 .53 \\
17.11 .53-3.12 .53 \\
4.12 .53-11.2 .54 \\
12.2 .54-30.4 .54 \\
\end{array}$ & $\begin{array}{l}327 \\
\text { ol4 } \\
367 \\
D^{7} \\
\text { Sel } \\
\end{array}$ \\
\hline & & & $\mathbf{R}$ & Few days & 5.10 .53 & $\begin{array}{l}\text { Ciliary injection, small corneal infiltrates, no } \\
\text { vascularization }\end{array}$ & As above fro & 5.10 .53 & $\begin{array}{l}\text { N } \\
\text { N }\end{array}$ \\
\hline
\end{tabular}

*See case history. Cortisone Dosage : Drops unless otherwise stated (Ung. = ointment). Visual Acuity': Snellen testesyp

ocular disease (iridocyclitis in acquired syphilis and choroiditis), but these cases are not reported here.

Groups.-For convenience of analysis the patients were divided into four groups :

Group $A, 8$ patients (12 eyes).-Cortisone started during first attack of interstitial keratitis (Table I).

Group B, 10 patients (10 eyes).-Previous attack in one eye. Cortisone started during first attack in other eye (Table II).
Group C, 2 patients (4 eyes).-Cortisone started elsewhere for first attack, and continued at Leeds (Table III).

Group D, 3 patients (3 eyes).-Cortisone used only for recurrence of previous attacks.

Cases 1, 9, and 11 have already been reported (Cases 3, 2, and 4 respectively of Horne, 1951).

General Management.-The majority of the 23 patients were admitted to hospital for initial treatment with topical cortisone (in Groups A and B three were admitted 
RST ATTACK OF INTERSTITIAL KERATITIS

\begin{tabular}{|c|c|c|c|c|c|c|c|}
\hline \multicolumn{3}{|c|}{ Antisyphilitic Treatment } & \multirow{3}{*}{ Clinical Response and Sequelae } & \multicolumn{4}{|c|}{ Most Recent Assessment } \\
\hline \multirow{2}{*}{$\begin{array}{l}\text { seni- } \\
\text { illin } \\
\text { mill. } \\
\text { inits) }\end{array}$} & \multirow{2}{*}{$\begin{array}{l}\text { Bismuth } \\
\text { (g.) }\end{array}$} & \multirow{2}{*}{$\begin{array}{l}\text { Date } \\
\text { Penicillin } \\
\text { Started in } \\
\text { Relation to } \\
\text { Cortisone } \\
\text { (days) }\end{array}$} & & \multirow{2}{*}{$\begin{array}{l}\text { Time } \\
\text { Since } \\
\text { Cortisone } \\
\text { Started } \\
\text { (mths) }\end{array}$} & \multirow{2}{*}{$\underset{\text { Data }}{\text { Clinical }}$} & \multicolumn{2}{|c|}{$\begin{array}{l}\text { Visual Acuity } \\
\text { (unaffected eye } \\
\text { in brackets) }\end{array}$} \\
\hline & & & & & & Right & Left \\
\hline 6 & $\begin{array}{l}2 \cdot 2 \\
2 \cdot 0 \\
16\end{array}$ & Plus 12 & $\begin{array}{l}\text { Excellent immediate response } \\
29.3 .51 \text {. Slit lamp-slight right aqueous flare (promptly } \\
\text { controlled by cortisone) } \\
\text { No relapse }\end{array}$ & 39 & $\begin{array}{l}\text { No abnormality } \\
\text { seen }\end{array}$ & $6 / 9$ & $6 / 6$ \\
\hline 8 & $\begin{array}{r}\cdot 0 \\
2 \cdot 0 \\
1 \cdot 8\end{array}$ & Minus 4 & $\begin{array}{l}\text { Good immediate response } \\
\text { Corneal infiltration slow in clearing, but quite clear } \\
\text { when cortisone stopped } \\
\text { No relapse }\end{array}$ & 33 & $\begin{array}{l}\text { Cornea clear, old } \\
\text { crenated keratic } \\
\text { precipitates }\end{array}$ & 6,12 & $(6 ; 6)$ \\
\hline \multirow[t]{2}{*}{4} & \multirow[t]{2}{*}{$\begin{array}{l}1 \cdot 0 \\
1 \cdot 5 \\
1 \cdot 5\end{array}$} & \multirow[t]{2}{*}{ Coincidental } & $\begin{array}{l}\text { Excellent immediate response } \\
\text { No relapse }\end{array}$ & 30 & \multirow[t]{2}{*}{$\begin{array}{l}\text { Central cornea } \\
\text { clear, slight } \\
\text { peripheral scar- } \\
\text { ring, no keratic } \\
\text { precipitates }\end{array}$} & \multirow[t]{2}{*}{$6 / 9$} & \multirow[b]{2}{*}{6,12} \\
\hline & & & $\begin{array}{l}\text { Excellent immediate response } \\
\text { No relapse }\end{array}$ & 26 & & & \\
\hline 8 & $\begin{array}{c}1.5 \\
1.6 \\
\text { (defaulted) }\end{array}$ & Plus 5 & $\begin{array}{l}\text { Excellent immediate response } \\
\text { 15.5.52. V.A. R.6; } 12 ; \text { L. } 6,9 \text {. } \\
\text { 6.6.52. Slit lamp-mild right iritis (promptly controlled } \\
\text { by cortisone) } \\
\text { No relapse }\end{array}$ & 23 & $\begin{array}{l}\text { Small superficial } \\
\text { nebulae in right } \\
\text { cornea only }\end{array}$ & $6 / 12$ & $6^{\prime} 6$ \\
\hline $\begin{array}{l}8 \\
5\end{array}$ & $\begin{array}{l}2 \cdot 0 \\
1 \cdot 4 \\
1 \cdot 0\end{array}$ & Plus 15 & $\begin{array}{l}\text { Good immediate response } \\
\text { 9.9.52. Large scattered keratic precipitates, patchy } \\
\text { infiltration of cornea, vessels from limbus } \\
\text { No relapse }\end{array}$ & 19 & $\begin{array}{l}\text { Slight corneal scar- } \\
\quad \text { ring }\end{array}$ & 6.9 & $(6 ! 12)$ \\
\hline 8 & $\begin{array}{l}2 \cdot 0 \\
2 \cdot 0 \\
2 \cdot 0\end{array}$ & Plus 27 & $\begin{array}{l}\text { Temporary improvement, then deterioration until } \\
\text { admission, then excellent immediate response } \\
21.12 .52 \text {. ? Slight reactivity (controlled by cortisone) } \\
\text { 21.2.53. Relapse-central nebula (controlled) } \\
\text { No further relapse }\end{array}$ & 18 & $\begin{array}{l}\text { Small scattered } \\
\text { nebulae only }\end{array}$ & 6,6 & $(6,6)$ \\
\hline 8 & $\begin{array}{c}2 \cdot 0 \\
\text { (defaulted) }\end{array}$ & Plus 3 & $\begin{array}{l}\text { Slow immediate response } \\
11.8 .53 \text {. C.F. Excellent response after admission } \\
\text { 21.8.53. V.A. } 6,9 \\
\text { No relapse }\end{array}$ & 8 & $\begin{array}{l}\text { No abnormality } \\
\text { seen }\end{array}$ & 66 & $(6,6)$ \\
\hline \multirow[t]{2}{*}{8} & \multirow[t]{2}{*}{10} & \multirow[t]{2}{*}{ Coincidental } & $\begin{array}{l}\text { Moderate immediate response, more rapid when } \\
\text { hydrocortisone substituted } \\
\text { Recurrence both eyes } 17.11 .53 \text { (promptly controlled by } \\
\text { cortisone) }\end{array}$ & 7 & \multirow[t]{2}{*}{$\begin{array}{l}\text { No activity (no } \\
\text { other data) }\end{array}$} & \multirow[t]{2}{*}{$6 / 12$} & \\
\hline & & & $\begin{array}{l}\text { Excellent immediate response } \\
\text { Recurrence (see above) }\end{array}$ & & & & $6 / 12$ \\
\hline
\end{tabular}

rrected for refractive errors $\quad$ (P.L. $=$ perception of light only ; H.M. $=$ hand movements only ; C.F. = counting fingers only).

after cortisone had been in use for 16,27 , and 67 days respectively, and five were treated entirely as out-patients ; both of Group C and one of Group D were admitted). Two of the patients who had relapses were re-admitted for further treatment. The periods of hospitalization are recorded in Tables I, II, and III (dates in italics), and in the section describing the results in Group D. The pupils of the affected eyes were maintained fully dilated with gutt. atropine sulphate ( 1 per cent.) and this was continued for variable periods after the control of the inflammation.

Cortisone Treatment.-The preparation used almost exclusively was a suspension in normal saline of cortisone acetate $(5 \mathrm{mg} . / \mathrm{ml}$.). Hydrocortisone suspension (5 mg. $/ \mathrm{ml}$.), cortisone ointment (15 mg./g.), and subconjunctival injections of cortisone $(0.25-0.5 \mathrm{ml}$. of a $25 \mathrm{mg} . / \mathrm{ml}$. suspension) were 
GROUP B, PREVIOUS ATTACK IN ONE EYE, CORTESON

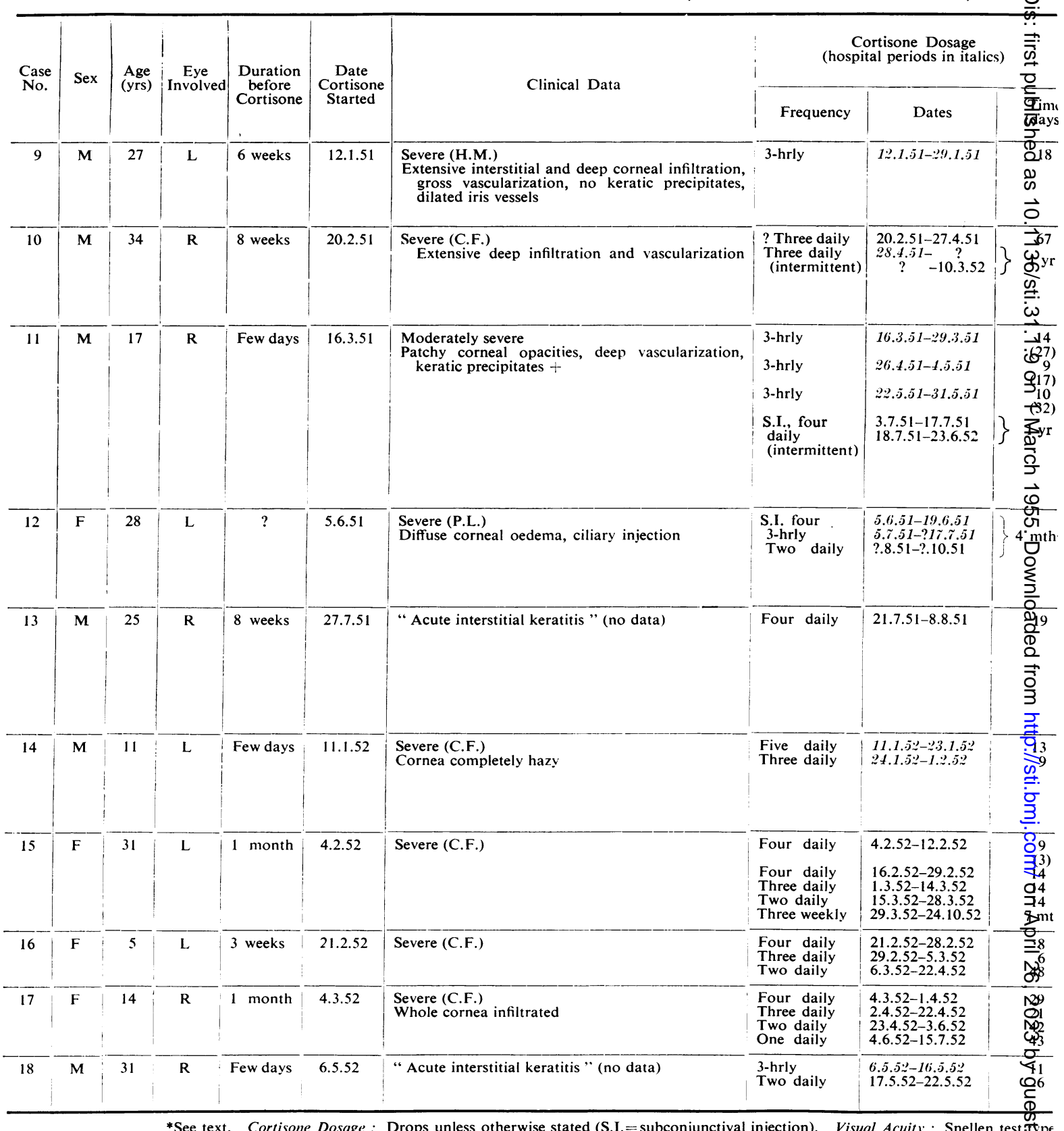

*See text. Cortisone Dosage : Drops unless otherwise stated (S.I.=subconjunctival injection). Visual Acuity : Snellen test.type

occasionally used. In-patients during the acute stage received one drop in the affected eye (or eyes) at intervals of from 1 to $4 \mathrm{hrs}$, depending mainly on the severity of the condition. For the first few days the drops were usually given " round the clock", but as improvement occurred the overnight doses were reduced and eventually omitted. One patient (Case 12) was given subconjunctival injections 
ARTED DURING FIRST ATTACK IN OTHER EYE

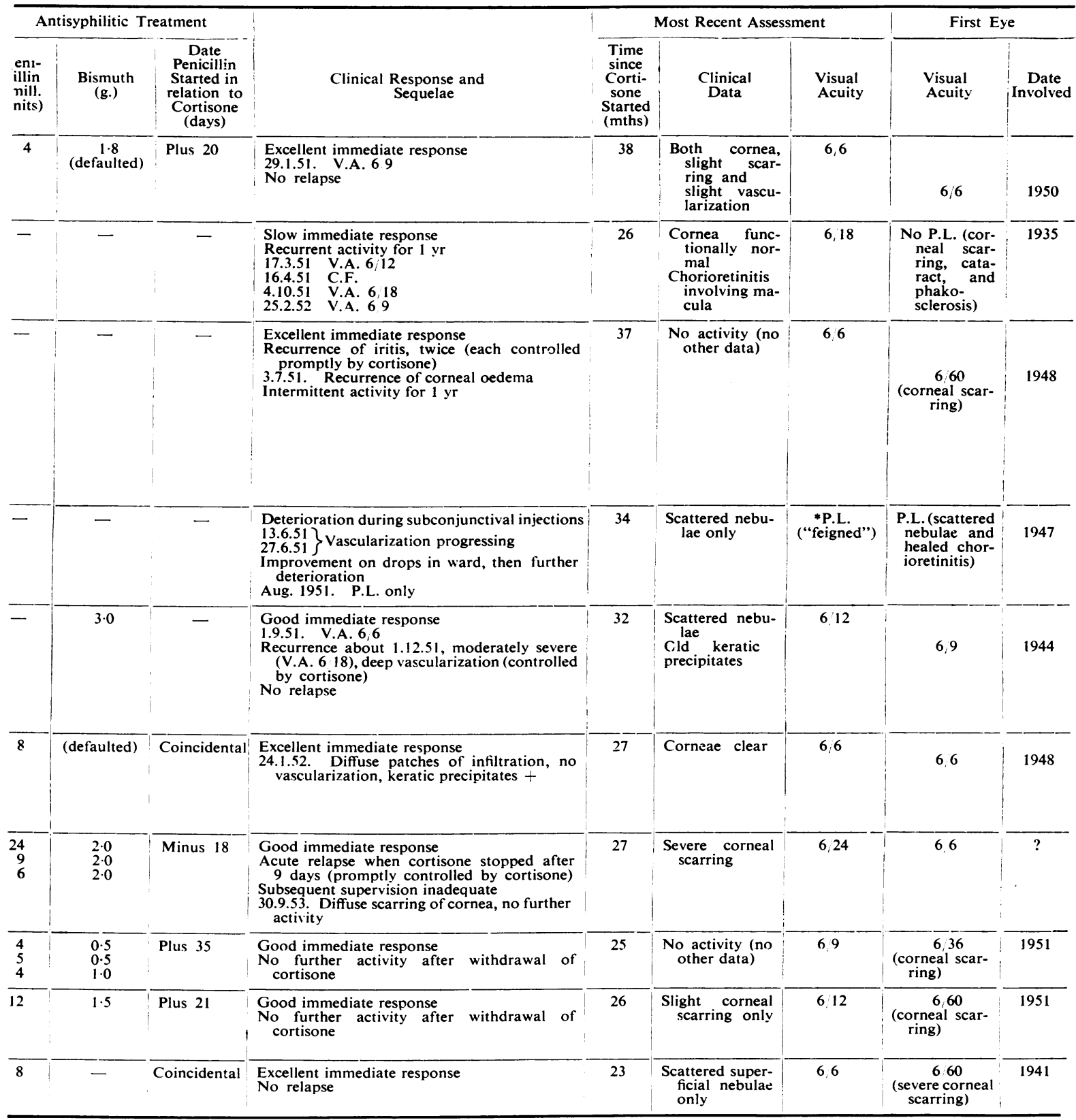

ected for refractive errors (P.L. - perception of light only; H.M. = hand movements only ; C.F. = counting fingers only).

initially. Cortisone was sometimes stopped for a period before the patient was discharged from hospital, sometimes it was stopped at the time of discharge but usually it was continued on an out- patient basis. The preparation, dosage, and duration of treatment used in individual patients are recorded in Tables I, II, and III, and in the section describing the results in Group D. 
TABLE III

GROUP C, CORTISONE STARTED ELSEWHERE FOR FIRST ATTACK, AND CONTINUED IN LEEDS

\begin{tabular}{|c|c|c|c|c|c|c|c|c|c|}
\hline \multirow{3}{*}{$\begin{array}{l}\text { Case } \\
\text { No. }\end{array}$} & \multirow{3}{*}{ Sex } & \multirow{3}{*}{$\begin{array}{l}\text { Age } \\
\text { (yrs) }\end{array}$} & \multirow{3}{*}{$\begin{array}{c}\text { Eye } \\
\text { Involved }\end{array}$} & \multirow{3}{*}{$\begin{array}{l}\text { Date Cortisone } \\
\text { Started }\end{array}$} & \multirow{3}{*}{$\begin{array}{c}\text { Clinical Data and } \\
\text { Treatment }\end{array}$} & \multicolumn{4}{|c|}{ Most Recent Assessment } \\
\hline & & & & & & \multirow{2}{*}{$\begin{array}{c}\text { Time since } \\
\text { Cortisone } \\
\text { Started } \\
\text { (mths) }\end{array}$} & \multirow{2}{*}{ Clinical Data } & \multicolumn{2}{|c|}{ Visual Acuity } \\
\hline & & & & & & & & Right & Left \\
\hline 19 & $\mathbf{M}$ & 16 & Bilateral & March, 1952 & 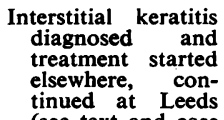 & 24 & $\begin{array}{l}\text { Both corneae, small cen- } \\
\text { tral nebulae and some } \\
\text { deep vascularization. } \\
\text { Left eye, some keratic } \\
\text { precipitates }\end{array}$ & $6 / 6$ & $6 / 18$ \\
\hline 20 & $\mathbf{M}$ & 9 & Bilateral & November, 1952 & histories) & 16 & $\begin{array}{l}\text { Both eyes, few keratic } \\
\text { precipitates only }\end{array}$ & $6 / 12$ & $6 / 9$ \\
\hline
\end{tabular}

Antisyphilitic Treatment.-None of Group A had had previous antisyphilitic treatment ; all of them were given a course of procaine penicillin (daily injections to a total of 4 to 8 million units), one starting 4 days before cortisone, two coincidentally with cortisone, the rest from 5 to 27 days after cortisone was started; all were subsequently given courses of bismuth (ten weekly injections of a metallic suspension). All of Group B had already had varying amounts of antisyphilitic treatment; six were given penicillin after the involvement of the second eye, and four of these and two others were given bismuth. Both of Group C had already had antisyphilitic treatment ; one was given further bismuth. All of Group D had already had antisyphilitic treatment; one was given further penicillin and bismuth, and another bismuth only.

\section{Results}

\section{Groups A, B, and C}

Immediate Response.-In all those patients in Groups A and B (" fresh " cases) who were treated from the beginning in hospital with drops, the immediate response was excellent, being similar to that experienced by other authors using a like dosage, as described above. On the whole, the earlier in the course of the disease cortisone was started the more rapid were the relief of symptoms, the suppression of activity, and the restoration of normal vision. The later cortisone was started, however, the more dramatic were the results. Even in cases where there was extensive and dense corneal infiltration and vision was reduced to counting fingers, or less (e.g. Case 8), the cornea cleared completely and vision was quickly restored to normal. One patient (Case 12) was initially given four subconjunctival injections at intervals of 3 to 4 days, but failed to improve until drops were started.

Seven patients started cortisone drops as outpatients. The condition of three of them continued to deteriorate until they were admitted and put on the following schedules :

Case 7, 2-hourly for 16 days ;

Case 6, 4-hourly for 27 days ;

Case 10, less frequently and intermittently for 67 days.

All three responded immediately after admission and the institution of high-dosage cortisone. The other four were treated entirely as out-patients, the drops being prescribed four times daily at first, and all responded well. One (Case 13) had a relapse but it was controlled by further cortisone (out-patient).

Hydrocortisone was used for only one patient (Case 8) : the whole cornea was extremely densely infiltrated, and improvement had been relatively slow with cortisone in spite of hourly drops. There appeared to be a signifcantly more rapid improvement when hydrocortisone was substituted, and the cornea eventually cleared completely.

The good immediate response occurred irrespective of whether the patients had received or were receiving penicillin, and of when they received penicillin in relation to cortisone (see Tables I and II and case histories). In Case 6 the improvement which followed admission to the ward and increased cortisone dosage coincided with the starting of penicillin.

Relapses and Recurrences.-The difficulty of interpreting, and even of recording, the incidence of relapses and recurrences has already been discussed. In two patients an acute relapse occurred as soon as cortisone was stopped prematurely against advice (after 9 days in Case 18 and after 6 weeks in Case 8). Case 13 had an acute relapse 4 months after the end of a course of cortisone as an out-patient (4 drops daily for 19 days). In Case 6 there was a slight symptomless infiltration of the cornea which was discovered 7 weeks after a course lasting 3 months had been stopped (see case history). One patient (Case 11) had two recurrences of iridocyclitis following an initial short course of 
cortisone ; each of these was promptly controlled by further short courses of cortisone, but there was an acute recurrence of interstitial keratitis a month after the end of the last course, and intermittent activity, requiring further courses of cortisone, persisted for a year. In Case 10 intermittent activity also persisted for about a year. Courses of cortisone had been given, but the dosage was only moderate or low, and the inflammation was never properly controlled. In Case 18, at a review 18 months after starting cortisone, considerable scarring of the cornea was found to have developed asymptomatically. There had been a good initial response, but, after adequate dosage for the first 2 months, a very low dosage had been used for a further 7 months.

In three patients (Cases 1, 4, and 20) slit-lamp evidence of mild iridocyclitis was discovered shortly after cortisone had been stopped, but in none of them was there any recurrence of activity in the cornea. In all these cases the relapses were promptly controlled by cortisone, and no further relapse occurred.

The case histories of both patients in Group C are quoted in detail (see Appendix) since they illustrate several interesting aspects of the problem. Case 19 had been treated (elsewhere) as an outpatient for acute bilateral interstitial keratitis with only moderate dosage of cortisone, and when the cortisone was stopped, about $3 \frac{1}{2}$ months after the onset of symptoms, there was an immediate relapse in one eye. This was quickly controlled and vision was restored to normal when high dosage was used in hospital at Leeds. A further relapse occurred when cortisone was stopped (against advice) after 5 weeks, but the patient was not seen again until several months later, by which time the whole cornea was opaque, $\mathrm{He}$ was re-admitted, and further cortisone controlled the condition, but even after intravenous ACTH the result in this eye was less satisfactory than in most of the other cases. This patient had been treated intensively with antisyphilitic drugs from the onset of interstitial keratitis up to the time of his arrival in Leeds. Each of the two relapses was controlled by cortisone without further antisyphilitic treatment apart from one 10 -week course of bismuth between the two relapses.

Case 20 also had been treated (elsewhere) as an out-patient for acute bilateral interstitial keratitis with moderate or low dosage of cortisone. The inflammation had apparently never been satisfactorily controlled, and 15 months after the onset of symptoms both eyes were still actively inflamed. After admission to hospital in Leeds and high dosage of cortisone the inflammation was rapidly controlled and vision restored to nearly normal.
Treatment was stopped after 27 days, and 3 weeks later there was slit-lamp evidence of mild iridocyclitis, which was promptly controlled with further cortisone, but no reactivity of the interstitial keratitis. This patient also had received intensive antisyphilitic therapy shortly before the onset, and during the early stages, of the keratitis. No further treatment was given after his arrival in Leeds.

Involvement of the Second Eye.-Of the eight patients in Group A, two had bilateral involvement before cortisone was started. In two of the remainder the second eye became involved, a few days (Case 8 ) and 4 months (Case 3 ) respectively after treatment of the first eye was begun. None of the other four has so far had involvement of the second eye. In one of the two patients in Group $\mathrm{C}$ there was bilateral involvement before cortisone was started (Case 19), and in the other the second eye became involved about a year after the first (Case 20).

Final Assessment.-A special review of all the twenty patients ( 26 eyes) in Groups A, B, and C was made in March and April, 1954. The examination included biomicroscopy and measurement of the visual acuity (corrected for refractive errors). None of the patients was receiving cortisone at the time of this review. The duration of observation after starting cortisone was as follows :

\begin{tabular}{l|c|c|c|c}
\hline Months .. & $6-11$ & $12-23$ & $24-35$ & $36-39$ \\
\hline No. of Eyes & 4 & 6 & 12 & 4 \\
\hline
\end{tabular}

The incidence of relapses and recurrences has already been discussed ; the incidence of corneal scarring and the final visual acuity are recorded in Tables I, II, and III. In only four of the 26 eyes was the visual acuity worse than $6 / 12$. In Case 12 it has been recorded as " perception of light only", but in fact her vision was very much better than this. There was only very faint corneal scarring through which the retina could be clearly seen and there was no evidence of active or healed choroiditis or of other ocular disease, but the patient would not cooperate for refraction. The cornea was perfectly clear when she was discharged from the ward after her initial course of cortisone and the nebulae developed while she was on a very low dosage of cortisone as an out-patient. For some reason, not yet elicited, this patient was uncooperative and preferred to feign blindness (there was only perception of light in the other eye as a result of corneal scarring and diffuse healed choroiditis); observations of her actions confirmed that vision could not be much impaired, and was probably in the region of $6 / 18$ or better.

In Case 10 (V.A. 6/18), in spite of the prolonged 


\begin{tabular}{|c|c|c|c|c|c|c|}
\hline \multirow{2}{*}{$\begin{array}{l}\text { Source of Data } \\
\text { No. of Patients }\end{array}$} & \multirow{2}{*}{$\cdots$} & \multirow{2}{*}{$\cdots$} & \multirow{2}{*}{$\frac{\begin{array}{c}\text { *Klauder and } \\
\text { Vandoren } \\
(1941)\end{array}}{\text { Not stated }}$} & \multicolumn{2}{|c|}{ Klauder (1947) } & 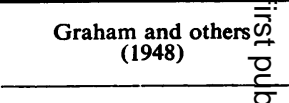 \\
\hline & & & & 54 & 59 & \multirow{2}{*}{ " 49 cases" $\frac{\bar{\sigma}}{\bar{\sigma}}$} \\
\hline No. of Eyes .. & .. & . & 63 & 96 & 97 & \\
\hline \multicolumn{3}{|c|}{ Treatment Schedule .. } & $\begin{array}{l}\text { Arsenic, bismuth, artificial } \\
\text { fever }\end{array}$ & $\begin{array}{c}\text { Arsenic, bismuth, artificial } \\
\text { fever }\end{array}$ & $\begin{array}{l}\text { Penicillin, with or without } \\
\text { fever and/or chemo- } \\
\text { therapy }\end{array}$ & $\begin{array}{l}\text { Arsenic and bismuth, sône } \\
\text { with fever }\end{array}$ \\
\hline \multicolumn{3}{|c|}{ Time of Assessment .. } & $\begin{array}{l}\text { At least } 1 \text { yr after starting } \\
\text { treatment }\end{array}$ & $\begin{array}{c}\text { About } 2 \frac{1}{2}-10 \\
\text { treatment }\end{array}$ & $1 \begin{array}{l}\text { yr or less after penicillin } \\
\text { treatment }\end{array}$ & $\begin{array}{l}\text { Unqualified, but probably } \\
\text { several years in most } \\
\text { cases }\end{array}$ \\
\hline \multirow{4}{*}{$\begin{array}{l}\text { Final Visual } \\
\text { Acuity } \\
\text { (corrected) } \\
\text { Percentage } \\
\text { Distribution }\end{array}$} & $6 / 60$ & better & $31 \cdot 7)_{55-5}$ & \multirow{2}{*}{$61 \cdot 5$} & $\left.20 \cdot 5\right|_{55.5}$ & \multirow{2}{*}{53} \\
\hline & \multicolumn{2}{|c|}{$6 / 9,6 / 12$} & $55 \cdot 5$ & & $55 \cdot 5$ & \\
\hline & \multicolumn{2}{|c|}{$6 / 15-6 / 30$} & $31 \cdot 7$ & $27 \cdot 5$ & $34 \cdot 0$ & 37 \\
\hline & \multicolumn{2}{|c|}{ Less than $6 / 30$} & $12 \cdot 7$ & 11.0 & $10 \cdot 5$ & 10 \\
\hline
\end{tabular}

*Visual acuity not " corrected" in every case. †One-patient, one eye (Case 12) omitted (see text). $\ddagger 3$ eyes : Visual Acuity : Case 15, $\overline{7} 24$

activity, the cornea was functionally normal and the impaired vision was almost certainly due to old choroiditis involving the macula.

In Cases 19 and 15 (V.A. 6/18 and 6/24 respectively), the impaired vision was probably due at least in part to corneal scarring. The management of both cases had been in some respects unsatisfactory, since corneal opacities were allowed to develop uncontrolled during a period when the patients were not under regular supervision, and when either no cortisone (Case 19) or inadequate dosage (Case 15) was being used. The visual acuity in the other eye in each of these patients is $6 / 6$.

For the purpose of comparison of this important criterion with other series of cases of interstitial keratitis these results have been summarized (excluding Case 12) in Table IV, which also assembles data adapted from the literature suitable for this purpose. The final visual acuity is shown in series treated with what were accepted as the best methods before cortisone was available. Table IV also includes two other cortisone-treated series (Oksala, 1953 ; North, 1954), with a relatively short observation period. In spite of the limitations of the interpretation of data of this type, there is no doubt that cortisone is much superior to all other methods of treatment.*

* Table IV confirms the view that penicillin has no advantage over chemotherapy in the treatment of interstitial keratitis, judged by chemotherapy in the treatment of interstitial keratitis, judged by
the final visual acuity. It also suggests that artificial fever therapy,
believed to be of value, did not have any great effect on the final visual acuity, although in the only series recorded here in which fever therapy was not used at all, a higher proportion of the eyes had a final visual acuity of less than 6/30. Whilst artificial fever would be expected to have a cortisone-like effect on interstitial keratitis, it is rarely used over long enough periods to control the infammation completely. Indeed, if it is true that inadequate dosage of local cortisone has an ultimate deleterious effect (see Discussion

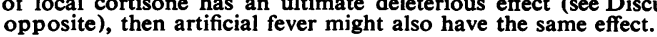

For the purpose of comparison, the final visual acuity of the 10 eyes in Group B treated without cortisone is included in Table II.

Group D.-The three patients in this series had all had bilateral interstitial keratitis previously, and cortisone was used only in the management of recurrences.

Case 23, male, aged 40, had a severe recurrence in one eye and was admitted to hospital on May 7, 1952. Cortisone drops were given initially five times daily, and the inflammation was rapidly controlled. Recurrent activity persisted, and intermittent courses of cortisone were continued on an out-patient basis until February 25, 1953. During this time he was given a course of procaine penicillin ( 8 million units) and three courses of bismuth (total $8.6 \mathrm{~g}$.). There was no further activity, and at a review 23 months after starting cortisone the visual acuity was $6 / 6$.

Case 22, male, aged 34, had a severe recurrence in one eye and started cortisone (one drop, three times daily as an out-patient) on March 5, 1952. The inflammation was controlled and cortisone stopped on April 24, 1952. The patient had a further severe attack in September, 1952 (visual acuity, counting fingers only), and restarted cortisone in the same dosage. The inflammation was controlled, and cortisone was stopped on October 6, 1952. The patient has not attended the hospital since, and it is assumed that he has had no further recurrence.

Case 21, male, aged 25, had a mild recurrence in both eyes and started cortisone (one drop, three times daily) on August 28, 1952. This was continued intermittently until February 23, 1953, when there was no slit-lamp evidence of activity. The visual acuity $(6 / 18,6 / 60)$ was the same as that before the onset of the recurrences treated with cortisone. The patient has not attended the hospital since, and it is assumed that he has had no further recurrence. 
? INTERSTITIAL KERATITIS

th series previously reported

\begin{tabular}{|c|c|c|c|c|}
\hline \multicolumn{3}{|c|}{ Oksala } & \multirow{2}{*}{ North (1954) } & \multirow{2}{*}{ †Present Investigation } \\
\hline (1952) & \multicolumn{2}{|c|}{ (1953) } & & \\
\hline Not stated & 24 & 11 & 8 & 19 \\
\hline 157 & 35 & 18 & 14 & 25 \\
\hline rsenic and bismuth & $\begin{array}{l}\text { Penicillin with or without } \\
\text { fever }\end{array}$ & $\begin{array}{l}\text { Penicillin, fever, and topical } \\
\text { cortisone }\end{array}$ & $\begin{array}{l}\text { Penicillin, with or without } \\
\text { bismuth and/or fever, and } \\
\text { topical cortisone }\end{array}$ & $\begin{array}{l}\text { Penicillin, bismuth, and topical } \\
\text { cortisone }\end{array}$ \\
\hline $\begin{array}{l}\text { Inqualified, but probably } \\
\text { many years in most cases }\end{array}$ & $\begin{array}{c}\text { Average } 1 \frac{1}{2} \text { yrs after treat- } \\
\text { ment }\end{array}$ & $\begin{array}{c}\text { Average } 1 \mathrm{yr} \text { after treat- } \\
\text { ment }\end{array}$ & $\begin{array}{l}\text { At least } 1 \text { yr after starting } \\
\text { cortisone }\end{array}$ & $\begin{array}{l}\text { 6-39 mths after starting } \\
\text { cortisone (see text) }\end{array}$ \\
\hline$\frac{22 \cdot 3}{31 \cdot 8} 54 \cdot 1$ & 60 & 100 & $\left.\frac{79}{21}\right\} 100$ & $52\}^{88}$ \\
\hline $27 \cdot 3$ & 26 & 0 & 0 & $\$ 12$ \\
\hline $18 \cdot 5$ & 14 & 0 & 0 & 0 \\
\hline
\end{tabular}

se $19,6 / 18$ - both have corneal scarring. Case 10,6/18-cornea functionally normal, but healed chorioretinitis involving macula (see text).

In these three cases of recurrences of previous attacks not treated with cortisone, the hormone was also of great value. The acute phase was suppressed, and in the two cases in which data are available, loss of vision from recurrent attacks was completely prevented.

\section{Discussion}

The results of treatment of this series of patients with syphilitic interstitial keratitis conform to the hypothetical discussion in the first part of this paper, and (where comparisons can be made) are as good as, or better than, the experience of most other observers who have used similar methods of treatment. Whilst there is no strictly comparable series of cases, treated without cortisone, available, there is no doubt that the results, immediate and longterm, are much superior to what would have been expected without cortisone, and in the cases considered to have been correctly managed, better results could hardly be imagined. This conclusion is drawn in spite of the small number of patients, and bearing in mind the notoriously fickle natural history of interstitial keratitis ; even without cortisone, good results are sometimes obtained (eventually) in even the most severe cases.

The best results were obtained on the whole in those patients who were admitted to hospital for their initial treatment. Where the progress and ultimate results were less good this can always be explained by some fault in the management of the case, through lack of cooperation on the part of the patient, inadequate supervision, and inadequate dosage of cortisone, or various combinations of these factors.
Since the majority of the patients were given shorter initial courses of cortisone than have been used by others (for example, by Ashworth, 1953, Drews and others, 1953), a relatively high relapse rate might have been expected, but this did not occur. This suggests that high initial dosage may tend to shorten the attack. There are not enough cases to justify drawing definite conclusions, but this possibility is supported by the observation that the cases in which activity persisted for very long periods (Cases 10, 11, 19, 20) are all those in which moderate or low dosage, or very short courses, had been used initially.

The results do not appear to have been influenced by systemic antisyphilitic therapy, except perhaps in relation to involvement of the second eye. Whilst in one patient (Case 11) with prolonged activity very little systemic treatment had been given, in others (Cases 19 and 20) there was prolonged activity in spite of intensive treatment; in one of the latter (Case 20) activity was controlled and apparently stopped with cortisone without any further systemic treatment being given.

\section{Conclusions}

From the reports in the literature and the series of 23 cases ( 29 eyes) reported here it is justifiable to conclude that if topical cortisone therapy is started soon after the onset of interstitial keratitis, and is used in adequate dosage and over a long enough period of time, the patient will obtain prompt relief of symptoms, no permanent damage will be done to the eye, and there will be no impairment of visual acuity. Even if cortisone is not started until the inflammation has been present for several weeks 
and dense infiltration and vascularization have occurred, the cornea can usually be cleared and vision restored to normal or near normal. In such cases failure should not be accepted until hydrocortisone (Compound F), and parenteral cortisone or ACTH (or, if these are not available, artificial fever), have been tried. There is little evidence to indicate that the use of cortisone in adequate dosage either prolongs an attack of interstitial keratitis or increases the likelihood of relapse. On the contrary, in the series reported here, the evidence seems to point the other way. Even if it is eventually proved that attacks are prolonged and recurrences more frequent, this is unlikely to be regarded as a contraindication to the use of cortisone. Topical cortisone is equally effective in controlling iridocyclitis accompanying interstitial keratitis. This form of treatment should now be accepted as imperative.

Cortisone should be started as soon as possible, and, ideally, all patients should be admitted to hospital immediately, in order that cortisone may be given under supervision. The patients should be kept in hospital at least until all evidence of activity of the disease is controlled, and until normal vision has been restored, though treatment can be given entirely on an out-patient basis if necessary. By "adequate" dosage is meant one drop of cortisone suspension 2- or 3-hourly, and even hourly, and "round the clock" if necessary in severe cases. Withdrawal of cortisone must necessarily be carried out empirically. Provided that the patient can be examined at frequent intervals, trial reduction can be started as soon as all signs of activity of the disease have disappeared, the cornea is clear, and visual acuity restored to normal. However, since there is some evidence to show that the ultimate progress may be influenced by the duration of high dosage, this should be continued for several weeks, irrespective of the rapidity of the immediate response. There is no evidence that harm can result from using high dosage over a long period of time. Indeed, in the series reported here there is some evidence that it is low dosage, without complete control of the inflammation, which tends to prolong the period of activity.

After cortisone is stopped, frequent and careful observation must be maintained, since insidious and symptomless relapses may occur, and evidence of iridocyclitis and corneal oedema and infiltration may be apparent only on slit-lamp examination. Cortisone should be restarted at the earliest sign of a relapse. Indolent infiltration of the cornea and keratic precipitates, if allowed to remain uncontrolled for a long period, may not be cleared by cortisone, and permanent opacity may result. Similar principles apply to the management of relapses, whether or not the original attack has been treated with cortisone.

There is no adequate evidence on the merits of the different methods of using local cortisone in interstitial keratitis, but it seems that hydrocortisone (Compound F) is superior to cortisone (Compound E) and that drops are the most efficient form of local application, especially in the initial stages of the disease; subconjunctival injections have rarely been as successful ; ointment may be useful overnight in the early stages, and for out-patient " maintenance" treatment.

Cortisone appears to be equally effective whether or not systemic antisyphilitic therapy is given coincidentally - thus supporting a "hypersensitivity" phenomenon as the pathological basis of the condition. Antisyphilitic therapy must, of course, be given.

If cortisone is used in the very early stages of a keratitis all evidence of inflammation is rapidly suppressed and the characteristic features of syphilitic interstitial keratitis are not allowed to develop. Care must therefore be taken to determine whether or not the patient has congenital syphilis. It should be remembered that standard serological tests are sometimes equivocal and even negative in active syphilitic interstitial keratitis ; confirmatory evidence of the disease must be sought and family investigations pursued if necessary.

\section{Summary}

(1) A review has been made of statements in the literature on the value of cortisone in the treatment of syphilitic interstitial keratitis. It is obvious that there is still some dubiety about its value. An attempt has been made to explain the contradictory reports that have been published, and the persisting reluctance to use cortisone in this condition.

(2) A brief discussion has been made of :

(a) the expected effects of cortisone on the natural history of syphilitic interstitial keratitis ;

(b) the practical aspects of its use in this disease ;

(c) the place of systemic antisyphilitic therapy ;

(d) the methods of assessing the effect of cortisone.

Experience recorded in the literature has been referred to when relevant to the points discussed.

(3) A detailed report is given of 23 patients (29 affected eyes) with syphilitic interstitial keratitis treated with topical cortisone, and kept under observation for periods ranging from 6 to 39 months after the start of treatment. It has been concluded that the correct use of topical cortisone produces 
results much superior to all previous methods of treatment.

(4) It has been concluded that topical cortisone is imperative in the treatment of syphilitic interstitial keratitis. An outline has been given of the best way of using it in this condition in the light of personal and recorded experiences.

The author is indebted to Mr. G. W. Black, Mr. J. Foster, and Mr. J. Sherne for their collaboration in the treatment of the patients. They do not necessarily agree with the views of the author. He is also indebted to the medical, nursing, and clerical staff of the Department of Venereal Diseases, General Infirmary, Leeds, and to Sister E. M. Gill, for their assistance.

\section{REFERENCES}

Ashworth, A. N. (1953). British Journal of Venereal Diseases, 29, 3. Crane, G. W., Jr., and McPherson, S. D., Jr. (1951). Amer. J. Syph., 35, 525.

Cole, H. N., Usilton, L. J., Moore, J. E., O'Leary, P. A., Stokes, J. H., Wile, U. J., Parran, T., and Vonderlahr, R. A. (1937). J. vener.Dis. Inform., 18, 97.

Drews, L. C., Barton, G. D., and Mikkelsen, W. M. (1953). Amer. J. Ophthal., 36, 90
Duke-Elder, S., Duthie, O. M., Foster, J., Law, F. W., Lister, A., Reid, A. M., Scott, G. I., Zorab, E. C., and Goldsmith, A. J. B. (1951). Brit. J. Ophthal., 35, 672.

Gordon, D. M. (1954). Amer. J. Ophthal., 37, 533.

-, McLean, J. M., and Koteen, H. (1953). Brit. J. Ophthal., 37, 85.

Graham, T. N., Romaine, H. H., and Rulison, R. H. (1948). N.Y. St. J. Med., 48, 1916.

Horne, G. O. (1951). Brit. med. J., 1, 1289.

(1954a). Brit. J. Ophthal., 38, 669.

- (1954b). Arch. Dis. Childh., 29, 123.

Klauder, J. V. (1947). Amer. J. Syph., 31, 575.

- (1951). J. vener. Dis. Inform., 32, 183.

- , and Meyer, G. P. (1954). Arch. Ophthal. (Chicago), 51, 432.

-

Laval, J. (1953). Arch: Ophthal. (Chicago), 50, 299.

Lavery, F. S. (1952). Trans. ophthal. Soc. U.K., 72, 193.

Lister, A. (1953). Abstr. Wld Med., 14, 111.

McDonald, P. R., Leopold, I. H., Vogel, A. W., and Mulberger, R. D. (1953). Arch. Ophthal. (Chicago), 49, 401.

Minton, J. (1952). Practitioner, 169, 530.

North, D. P. (1954). Brit. med. J., 2, 7.

Oksala, A. (1952). Acta ophthal. (Kbh.), Suppl. 38.

-(1953). Amer. J. Syph, 37, 540.

Purnell, J. E., and Leopold, I. H. (1952). Amer. J. Ophthal., 35, 663.

Salomaa, S., and Swanljung, H. (1952). Acta Ophthal. (Kbh.), $30,53$.

Steffensen, E. H. (1952). J. Amer. med. Ass., 150, 1660.

- Ivy, H. B., and Nagle, F. O. (1952). Amer. J. Ophthal., 35, 933.

Woods, A. C. (1950). Ibid., 33, 1325.

-(1951). Amer. J. Syph., 35, 517.

(1952a). Brit. J. Ophthal., 36, 401. (1952b). Trans. ophthal. Soc. U.K., 72, 171.

\section{A P P E N D I X}

\section{Case Histories}

Case 6, male, aged 23, developed interstitial keratitis in the right eye at the end of September, 1952 (Wassermann reaction positive; diagnosis of congenital syphilis confirmed later). In spite of cortisone drops prescribed 4-hourly as an out-patient from October 1, 1952, the condition deteriorated: ciliary injection persisted, the whole of the cornea became oedematous, but there was no vascularization; visual acuity was reduced to counting fingers at $1 \mathrm{ft}$. He was admitted on October 28, 1952. Cortisone drops were given 2hourly until November 7, 1952 (when he was discharged from hospital), and thereafter four times daily until November 21, 1952. By this time the cornea had completely cleared, and visual acuity was $6 / 9$. Cortisone was then reduced to once daily until December 21, 1952, when slight activity was suspected, and the dose increased to four times daily. Cortisone was stopped on January 1, 1953, when the cornea was clear again and there was no evidence of activity.

A course of procaine penicillin ( 8 million units) was started on October 27, 1952, and was followed by weekly injections of $0.2 \mathrm{~g}$. bismuth. The stopping of cortisone on January 3, 1953 coincided with the end of the first course of bismuth $(2 \mathrm{~g}$.). When the patient returned 6 weeks later on February 21, 1953, he was found to have a large central nebula in the right eye. There had been no local symptoms to draw attention to the recrudescence. Cortisone was prescribed as an out-patient 2-hourly (during waking hours) for 25 days, until March 16, 1953, when it was stopped. The nebula had completely cleared.

Two further courses of bismuth (each of $2 \mathrm{~g}$.) were given. At his last review on March 22, 1954 (18 months after starting cortisone), there was no evidence of any activity in the eye. There were a few small scattered nebulae in the cornea and a few faint vessels. The visual acuity was $6 / 6$. The left eye has not been involved clinically, and was normal on slit-lamp examination.

Case 19, male, aged 16, developed bilateral interstitial keratitis (blood Wassermann reaction positive ; Hutchinsonian incisors) at the end of March, 1952, and was treated at a hospital elsewhere. Cortisone had apparently been given initially as subconjunctival injections, and the inflammation had been controlled in both eyes. Cortisone was continued as drops, but these had been used spasmodically. He had also been given a large amount of treatment with penicillin, arsenic, and bismuth. He moved into the Leeds area, and was first seen here on August 8, 1952. Cortisone had been stopped about 3 weeks previously. In the right eye there was a very small nebula, no evidence of active disease, and the visual acuity (corrected) was $6 / 6$; in the left eye there was severe pain, blepharospasm, photophobia, lacri- 
mation, circumcorneal injection, and dense infiltration of the whole of the cornea ; visual acuity was reduced to counting fingers at $1 \mathrm{ft}$.

He was admitted immediately (August 8, 1952) and cortisone drops were administered 4-hourly " round the clock" for 12 days, then twice daily for 12 days. The immediate response was excellent, and when he was discharged from the ward on September 1, 1952, the left cornea was clear, and visual acuity (corrected) 6/6. Arrangements were made for his supervision at a clinic elsewhere in the area. He was next seen here 7 months later, on March 31, 1953, when the left cornea was found to be completely hazy, and vision reduced to counting fingers at $1 \mathrm{ft}$. Apparently cortisone had been continued for only 2 weeks, but he had attended for ten weekly injections of bismuth. There was no pain, photophobia, or lacrimation, and, presumably since the loss of vision had been gradual, he had no complaints. In the right eye there was an aqueous flare, but no other evidence of activity

He was re-admitted on April 8, 1953, and cortisone drops were administered to both eyes 2-hourly until May 9, 1953, and then 2-hourly as an out-patient until May 18, 1953. Most of the cornea cleared rapidly, but at the end of this time there was still a fairly dense central infiltrate and visual acuity was only $6 / 18$. He was re-admitted, and between May 19, 1953, and May 27, 1953, he was given four 8-hour intravenous drips, each of $25 \mathrm{mg}$. ACTH in a litre of saline. This did not result in any significant local improvement. Topical cortisone was restarted (four times daily) and continued until July 22, 1953. At this time there was no evidence of activity in either eye, but there was a small residual nebula in each cornea. The visual acuity in the right eye was 6/6, and in the left eye 6/18.

At a review on March 27, 1954, visual acuity was still $6 / 6$ in the right eye, and $6 / 18$ in the left. There was a small central nebula and some deep vascularization in both eyes, but no evidence of inflammatory activity ; some keratic deposits were seen on the back of the nebula in the left eye.

Case 20, male, aged 9, developed acute interstitial keratitis in October, 1952, whilst under treatment elsewhere for congenital syphilis which had presented as osteitis of the tibia (blood Wassermann reaction positive ; Hutchinsonian incisors). He had been treated with cortisone drops as an out-patient, initially 3-hourly for 10 days. There had been a good response, but the condition soon relapsed, and, in spite of continued cortisone therapy, had remained more or less active for over a year. Apparently the drops had been used only once or twice daily, and probably only intermittently. The left eye had become involved about a year after the right one, and had also been treated with only low dosage of cortisone. During this time the patient had had a large amount of treatment with penicillin, arsenic, and bismuth.

He moved into the Leeds area, and was first seen here on January 25,1954 . The left eye showed deep corneal oedema and infiltration and keratic precipitates; the visual acuity was 6/12. The right eye was also still active, with deep vascularization; the visual acuity was 6/12. The patient was admitted immediately, and cortisone drops prescribed for both eyes 2-hourly until February 5, 1954, and then 4-hourly. There was rapid improvement, and by February 11, 1954, there was no evidence of activity, though some residual scarring was present in both corneae. Cortisone was stopped on February 21, 1954. On March 23, 1954, there was no activity in the right eye, but in the left eye there was slit-lamp evidence of iritis. Cortisone 2-hourly was immediately restarted. When it was stopped on April 2, 1954, there was no evidence of activity in either eye, and the visual acuity was $6 / 12$ in the right eye and $6 / 9$ in the left. No further antisyphilitic treatment had been given. 